\title{
usm \\ $\sim$

\section{A privatização da educação brasileira e a BNCC do Ensino Médio: parceria para as competências socioemocionais}

\author{
The privatization of brazilian education and the BNCC for Secondary \\ Education: partnership for the socioemotional skills
}

\begin{abstract}
Rafael Rodrigo Mueller
Professor doutor na Universidade do Extremo Sul Catarinense, Criciúma, Santa Catarina, Brasil. rrmueller@unesc.net - https://orcid.org/0000-0001-6637-2948
\end{abstract}

André Cechinel

Professor doutor na Universidade do Extremo Sul Catarinense, Criciúma, Santa Catarina, Brasil. andrecechinel@unesc.net - https://orcid.org/0000-0002-6620-3447

Recebido em 16 de novembro de 2018

Aprovado em 22 de fevereiro de 2019

Publicado em 14 de maio de 2020

\section{RESUMO}

Este artigo pretende discutir as consequências da parceria entre o Ministério da Educação (MEC) e órgãos nacionais e internacionais que assumiram o papel de reguladores transnacionais de políticas de educação em diversos países, especialmente os chamados países "em desenvolvimento". Para tanto, pretende-se analisar como a Organização para a Cooperação e Desenvolvimento Econômico (OCDE) e o Instituto Ayrton Senna (IAS) influenciam a educação brasileira a partir da recém aprovada Base Nacional Comum Curricular (BNCC), como forma de demonstrar objetivamente a relação entre essas instituições e sua lógica privada e comercial que tem influenciado as políticas públicas nacionais centrada, em grande medida, no conceito de competências socioemocionais. Portanto, o estudo utiliza como referência central para tal articulação a própria BNCC, em especial a do ensino médio, uma vez que essa etapa da educação básica é aquela em que as categorias trabalho e educação estão mais intensas e concretamente relacionadas.

Palavras-chave: Privatização; Educação Brasileira; Base Nacional Comum Curricular.

\section{ABSTRACT}

This paper intends to discuss the consequences of the partnership between the Brazilian Ministry of Education (MEC) and national and international agencies that have assumed the role of transnational regulators of education policies in several countries, especially the so-called "developing" countries. In order to do so, we intend 


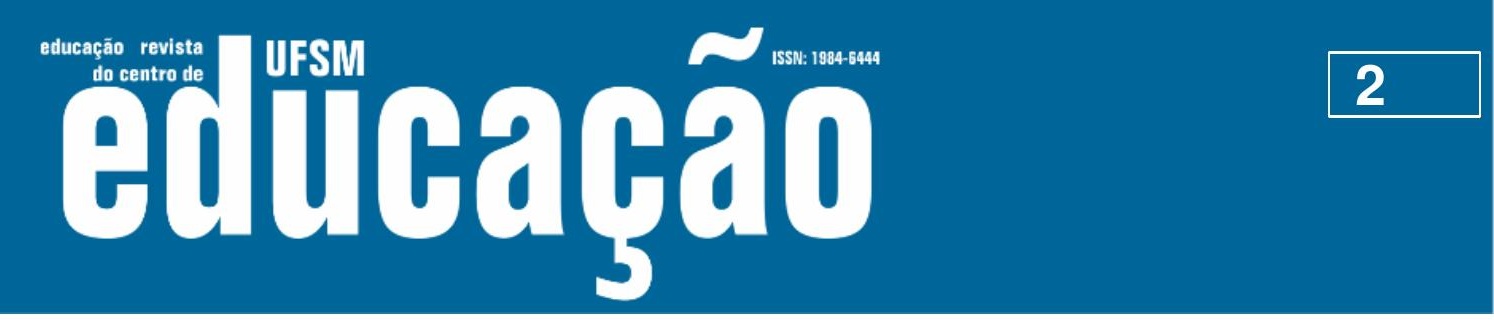

ISSN: 1984-6444 | http://dx.doi.org/10.5902/1984644435680

to analyze how the Organization for Economic Cooperation and Development (OECD) and the Ayrton Senna Institute (ASI) objectively influence national education Brazilian education from the recently approved National Curricular Common Base (NCCB) as a way of objectively demonstrating the relationship between these institutions and their private and commercial logic that has influenced national public policies centered to a large extent on the concept of socioemotional skills. Therefore, the study uses BNCC as central reference for such articulation, especially the one of secondary education, since this stage of basic education is one in which the categories of work and education are more intense and concretely related..

Keywords: Privatization; Brazilian Education; National Common Curricular Base.

\section{Introdução}

No dia 30 de maio de 2017, o Brasil formalizou o seu desejo em aderir a Organização para a Cooperação e Desenvolvimento Econômico (OCDE). Tal desejo não é recente, pois desde 1994 vem acompanhando regularmente 23 comitês e grupos de trabalho, já cedendo a 31 dos instrumentos jurídicos acordados por seus membros e desde 2007 é considerado pela organização como um parceiro engajado (BBC, 2018). Pode-se perceber o impacto interno de tal adesão quando em 2015, no Relatório Econômico sobre o Brasil, a OCDE recomendou a constituição de uma regra de gastos nacional, fato que resultou na Proposta de Emenda à Constituição (PEC) 241 de 2016, restringindo os gastos públicos com educação e saúde pelos próximos 20 anos.

Para além do âmbito estritamente econômico, a observância de regras impostas pela organização ao Brasil pode ser percebida na esfera educativa a partir de recomendações específicas e pela interferência em políticas públicas educacionais, mais bem explicitadas pela tríade trabalho, educação e qualificação profissional, a qual é permeada pelo nó górdio da relação entre competências e habilidades em todos os níveis educacionais. No país, tal relação historicamente vem se objetivando em grande parte a partir da década de 1990, constatação visível pelas diversas pesquisas e publicações entusiastas e críticas desta condição, ampliada nos anos 2000 e potencializada na presente década pela inserção da demanda educacional das competências socioemocionais (OCDE, 2015). 


\section{Autตaดูão}

ISSN: 1984-6444 | http://dx.doi.org/10.5902/1984644435680

condições socioeconômicas, e seus respectivos níveis de escolarização, o que sugere a intervenção objetiva por parte dos diversos atores envolvidos em tal processo (gestores, educadores, organizações sociais, entidades representativas) visando a transformação de tal condição por meio de políticas públicas que oportunizem condições consideradas dignas de trabalho, educação, saúde, moradia etc. Tal preocupação expressa em suas entrelinhas um processo que vem se avolumando no Brasil desde a década de 1990 com o sistemático avanço de políticas neoliberais junto aos governos federais: o que inicialmente apresenta-se como uma salutar parceria entre os entes federais e privados, indica de fato a real intervenção destes últimos (organizações sociais e organismos multilaterais) naquilo que cabe ao Estado enquanto direitos garantidos constitucionalmente, nesse caso em particular, o acesso a uma educação socialmente referenciada.

A preocupação explícita por parte da OCDE e IAS no que se refere ao desenvolvimento e implementação de políticas educacionais que em sua origem tenham um referencial pautado pelo aprimoramento de competências cognitivas (letramento, conhecimentos lógico-matemáticos e científicos) e não cognitivas (perseverança, autonomia, curiosidade etc.) (SANTOS; PRIMI, 2014), é um indicativo objetivo da necessária vinculação entre educação e economia como forma de combater desigualdades centradas nos indivíduos e não na lógica mercantilempresarial. Esses indivíduos que já são e que ainda podem fazer parte da população economicamente ativa devem ser aprimorados por um processo contínuo e efetivo de escolarização centrado em políticas públicas que concebam essa mesma população enquanto um ativo imprescindível para o desenvolvimento social e o crescimento econômico, conforme a fala do então Ministro da Educação José Henrique Paim durante o Fórum Internacional de Políticas Públicas, promovido pela OCDE e MEC em 2014: "O desenvolvimento de competências tem consequências sobre a desigualdade social: promover as competências certas por meio da educação é uma ferramenta importante que governos devem considerar para diminuir as lacunas entre resultados educacionais, econômicos e sociais" (FÓRUM INTERNACIONAL, 2014, p. 02). 


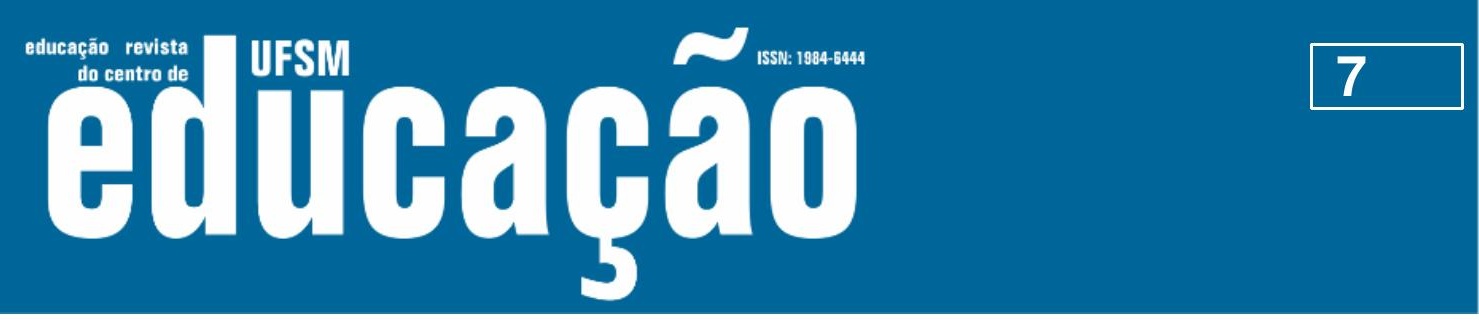

ISSN: 1984-6444 | http://dx.doi.org/10.5902/1984644435680

Sob vários aspectos, podemos considerar o fórum internacional de 2014 como o marco referencial para a parceria que se estabeleceu e vem se fortalecendo entre o MEC, a OCDE e o IAS, em particular entre os dois últimos, tendo em vista o número de publicações e estudos veiculados pelas inúmeras organizações sociais relacionadas ao IAS, dentre elas: o Movimento Todos pela Educação, o Movimento pela Base Nacional Comum e o Itaú Social, braço educacional do Banco Itaú. Ainda em 2014, a Coordenação de Aperfeiçoamento de Pessoal de Nível Superior (CAPES), órgão vinculado ao MEC voltado para a Pós-Graduação stricto sensu, lançou um edital público do Programa de Apoio à Formação de Profissionais no Campo das Competências Socioemocionais (n. 44/2014) em parceria com o Instituto Ayrton Senna. O programa visa incentivar pesquisas sobre o desenvolvimento de competências e habilidades socioemocionais na educação, fomentando a produção acadêmica e formação de professores, sendo que referido edital aprovou dez projetos prevendo o financiamento anual de até $R \$ 566.440,00$ para cada um destes. Este projeto, firmado entre o MEC e o IAS, é resultado das articulações feitas durante o fórum mundial como forma de demonstração objetiva de que o governo brasileiro se coloca em plena sintonia com as demandas advindas da OCDE em termos de acomodar em sua estrutura curricular educacional e na formação continuada de professores, as tendências globais para a educação do século XXI, centradas em uma neoliberal.

Desde então, uma série de projetos e parcerias com estados brasileiros foram capilarizando, até o âmbito escolar, as concepções de competências socioemocionais e de educação integral: em 2014, o IAS em parceria com o CERI/OCDE e a Secretaria de Estado do Rio de Janeiro publica um amplo relatório intitulado Desenvolvimento socioemocional e aprendizado escolar: uma proposta de mensuração para apoiar políticas públicas. Esse relatório descreve o planejamento, a execução e os resultados obtidos a partir do Projeto de Medição de Competências Socioemocionais, o qual envolveu cerca de 25.000 alunos de escolas públicas do ensino fundamental e médio. O objetivo deste projeto foi "elaborar um instrumento confiável para a mensuração de competências socioemocionais em larga escala e validá-lo empiricamente através da 


\section{Autตaคูão}

ISSN: 1984-6444 | http://dx.doi.org/10.5902/1984644435680

aplicação piloto em uma amostra representativa de alunos da rede estadual de educação do Rio de Janeiro" (SANTOS; PRIMI, 2014, p. 05).

Já o programa Letramento em Programação constituiu-se por meio da formação de educadores, criando possibilidades de inserção de alunos no universo digital utilizando ferramentas gratuitas de programação computacional. Criado em 2015, o projeto chegou a mais de 700 estudantes em quatro municípios dos estados de São Paulo e Rio Grande do Sul por meio da formação de educadores. Conforme o próprio instituto, para além da prática da programação "os alunos e educadores desenvolvem, de maneira integrada, competências cognitivas e socioemocionais fundamentais para a vida no século 21 , como criatividade, resolução de problemas, colaboração e persistência" (IAS, 2018). Ainda em 2015, o instituto desenvolve o programa Gestores em Rede que atua em parceria com onze municípios de sete estados brasileiros. A partir de uma plataforma online centrada em encontros virtuais e presenciais, o instituto medeia a troca de experiências entre os diversos gestores participantes. O propósito do programa é "a construção conjunta de um repertório robusto de estratégias de boas práticas da gestão educacional, a ser compartilhada com um maior número de redes de ensinos" (IAS, 2018).

Em 2016, preocupados em promover a educação integral de alunos matriculados nos três primeiros anos do ensino fundamental, o IAS concebe em parceria com as redes de ensino de três municípios, uma série de referenciais pedagógicos e ferramentas de gestão que contribuem para a construção políticas públicas de alfabetização, onde não somente se desenvolva o letramento clássico, mas também o "letramento corporal, científico e socioemocional" (IAS, 2018). Tal projeto intitulado Gestão da Política de Alfabetização, em 2017 atua em seis municípios de seis estados distintos, mais um conjunto de 21 municípios agrupados por meio de um arranjo de desenvolvimento da educação, da região de Florianópolis, capital de Santa Catarina. Ainda nesse mesmo estado, inspirada em uma proposta concebida originalmente no estado do Rio de Janeiro, é firmada uma parceria entre IAS, Secretaria de Educação de Santa Catarina (SED-SC), Banco Interamericano de Desenvolvimento (BID) e Federação das Indústrias de Santa Catarina (FIESC), a partir da Proposta de Educação Integral para o Ensino Médio. Desde 2017, esta prevê 


\section{F WEM Eltothato

ISSN: 1984-6444 | http://dx.doi.org/10.5902/1984644435680

o suporte à Secretaria de Educação para a elaboração de modelos de currículo, formação de professores e avaliação orientados para a promoção da educação integral, sendo inicialmente implantada em quinze escolas do estado, número que foi ampliado para trinta em 2018. Segundo o instituto, o objetivo da proposta é "oferecer oportunidades para os estudantes se desenvolverem com autonomia, e tem como premissa uma matriz de competências e conceito de educação integral que prevê a ampliação do tempo na escola" (IAS, 2018).

Ao final do ano de 2017, instituiu-se no Brasil a Base Nacional Comum Curricular (BNCC) que tem entre suas principais premissas, o desenvolvimento de uma educação integral (BNCC, 2017). Nesse sentido, o documento compreende que a educação deve centrar-se primordialmente em questões voltadas à "formação e ao desenvolvimento humano global, o que implica compreender a complexidade e a não linearidade desse desenvolvimento, rompendo com visões reducionistas que privilegiam ou a dimensão intelectual (cognitiva) ou a dimensão afetiva" (BNCC, 2017, p. 14), sendo que ambas as dimensões citadas dizem respeito aos conteúdos relacionados às competências cognitivas e não-cognitivas (socioemocionais). Constatamos a partir dos elementos conceituais presentes no texto da BNCC, a forma como historicamente os preceitos desenvolvidos e defendidos pela OCDE e IAS vão sendo incorporados no núcleo formativo e orientador da educação pública brasileira via a integração curricular e pela consequentemente necessária formação de professores. Pensando nestas questões, o IAS (2018) desenvolve um guia digital intitulado BNCC: construindo um currículo de educação integral no qual expõe "uma análise exclusiva que relaciona 10 competências gerais descritas na BNCC às competências socioemocionais cientificamente identificadas como importantes de serem consideradas e desenvolvidas no contexto escolar brasileiro". O objetivo é auxiliar os atores envolvidos na elaboração dos currículos das redes de ensino municipais e estaduais como forma de garantir o compromisso com a educação integral indicada pela BNCC.

Concentrando o seu foco de atenção no desenvolvimento e efetivação da BNCC junto à educação brasileira, o IAS promove em maio de $2018 \mathrm{em}$ parceria com o Itaú Social o Ciclo de debates em Gestão Educacional: a formação de professores 


\section{U usm \\ ISSN: 1984-6444 \\ elithahá}

ISSN: 1984-6444 | http://dx.doi.org/10.5902/1984644435680

2017. Em sua avaliação final tanto do processo de discussão quanto do texto da BNCC, as conselheiras Aurina de Oliveira Santana, Malvina Tania Tuttman e Marcia Angela da Silva Aguiar - a última, vale lembrar, presidente da comissão bicameral quando de sua constituição inicial - decidiram pelo pedido de vistas e posterior voto em separado contrário à aprovação do documento. Segundo o voto da Conselheira Márcia Angela da Silva Aguiar, o texto final da BNCC apresenta "lacunas e incompletudes, abdica do seu papel como órgão de Estado; fragiliza a formação integral dos estudantes, além de ferir a autonomia dos profissionais da Educação" (apud AGUIAR, 2018, p. 21). O tom de reprovação permanece o mesmo nos outros dois pareceres, que reafirmam a precariedade democrática do processo. $O$ voto de Malvina Tania Tuttman é claro nesse sentido:

reitero o meu posicionamento contrário ao Parecer, por ser favorável ao diálogo democrático e republicano [...]. Concluo, afirmando que lutarei para que o diálogo democrático e republicano aconteça em todos os espaços e recantos do Brasil, inclusive neste colegiado (apud AGUIAR, 2018, p. 21).

Em sua apresentação redigida para o texto final da BNCC, em contradição com os pareceres das conselheiras acima citados, o então Ministro da Educação, José Mendonça Bezerra Filho, cuja formação localiza-se na área de Administração de Empresas, declara que "a BNCC é fruto de amplo processo de debate e negociação com diferentes atores do campo educacional e com a sociedade brasileira e encontrase organizada em um todo articulado e coerente fundado em direitos de aprendizagem" (BRASIL, 2018, p. 5). O documento estrutura-se, como ficamos sabendo desde o texto introdutório, sobre dez competências gerais para a Educação Básica, que devem se inter-relacionais nas três etapas da Educação Básica no sentido de promover a construção de conhecimentos, o desenvolvimento de habilidades e a formação de atitudes e valores, conforme indicado na própria LDB. A título de exemplo, a primeira das competências gerais afirma o seguinte: 


\section{usm

ISSN: 1984-6444 | http://dx.doi.org/10.5902/1984644435680

Valorizar e utilizar os conhecimentos historicamente construídos sobre o mundo físico, social, cultural e digital para entender e explicar a realidade, continuar aprendendo e colaborar para a construção de uma sociedade justa, democrática e inclusiva (BRASIL, 2018, p. 9).

Como no caso desta, as outras nove competências serão acionadas em diferentes momentos do texto, operando como pontos articuladores de tudo o que está posto na Base.

Segundo o texto, por competência entende-se "a mobilização de conhecimentos (conceitos e procedimentos), habilidades (práticas, cognitivas e socioemocionais), atitudes e valores para resolver demandas complexas da vida cotidiana, do pleno exercício da cidadania e do mundo do trabalho" (BRASIL, 2018, p. 8). Parece haver, por parte dos leitores mais críticos da BNCC, uma espécie de consenso de que não só essa definição de competência acentua certa instrumentalização tecnicista do currículo, como também carece de um vínculo mais claro com a ideia de formação integral que o documento insistentemente cita também sem conceituar. Em 14 de maio de 2018, a ANPEd, Associação Nacional de Pós-Graduação e Pesquisa em Educação, emite uma nota criticando, entre outros pontos - como a falta de legitimidade da proposta e o esvaziamento do currículo -, exatamente a vagueza da noção de competência ali elaborada. Segundo a ANPEd (2018),

[...] a ênfase na aprendizagem para desenvolver competências, sabemos, está articulada com as políticas que o Banco Mundial e outros organismos internacionais vêm desenvolvendo nos últimos tempos, e tem a ver com pensar a escola como se fosse uma empresa.

Nesse sentido, a centralidade da noção de competência, que permanece sem uma definição clara e direcionada à lógica de meios e fins e de um saber fazer-

por meio da indicação clara do que os alunos devem "saber" e, sobretudo, do que devem "saber fazer" [...], a explicitação das competências oferece referências para o fortalecimento de ações que assegurem as aprendizagens essenciais definidas na BNCC (BRASIL, 2018, p. 13) 


\section{U usm etituará}

ISSN: 1984-6444 | http://dx.doi.org/10.5902/1984644435680

matemática. Em outras palavras, como se sabe, para além da lógica das competências e habilidades que compõem as quatro áreas do conhecimento Linguagens e suas tecnologias, Matemáticas e suas tecnologias, Ciências da natureza e suas tecnologias e Ciências humanas e sociais aplicadas -, a BNCC mantém apenas português e matemática como disciplinas obrigatórias, reduzindo as disciplinas anteriores como história, geografia, sociologia, filosofia, educação física, artes etc. a meros temas transversais que aparecem diluídos aqui e ali sob a forma de habilidades. Conforme destaca mais uma vez a nota publicada pela ANPEd (2018),

reconhecer apenas a matemática e a língua portuguesa como disciplinas curriculares e transformar as demais disciplinas do atual currículo em componentes e temas transversais, traz certamente um enorme prejuízo do ponto de vista da formação humana e técnico-científica para os estudantes.

Ora, essa redução curricular assume um caráter explicitamente tecnicista que contrasta uma vez mais com os pressupostos de formação integral destacados pelo próprio documento, que, aliás, parece confundir - embora afirme que não o faça - o que significa formação integral - que sob conceituação alguma poderia prescindir da arte, literatura, filosofia, sociologia, educação física etc. para a sua promoção - com formação em tempo integral, que se refere especificamente ao número de horas que a pessoa permanece na escola para a formação. Seja como for, fica difícil conceber, por um lado, como um processo educativo centrado em uma perspectiva claramente cognitivista e em apenas duas disciplinas, português e matemática, poderia promover qualquer ideia de educação integral. Por outro lado, o motivo da centralidade de português e matemática parece bastante claro: sob o pressuposto conveniente de um conceito de interdisciplinaridade capaz de acolher em si todas as disciplinas, buscase por meio da BNCC maior sintonia com os exames conduzidos pelo Pisa e pela OCDE. Nas palavras de Maria Helena Guimarães de Castro, secretária executiva do MEC, "a interdisciplinaridade é tendência no mundo todo. No exame (internacional) do Pisa não se vê, em ciências, o que é biologia, química ou física, tudo está ligado" (apud CAFARDO, 2018). Nessa lógica, tudo está ligado, menos, a princípio, matemática e português. 


\section{Autharẫ}

ISSN: 1984-6444 | http://dx.doi.org/10.5902/1984644435680

Por fim, em determinada etapa do Ensino Médio, o afunilamento curricular se acentua ainda mais e os alunos devem escolher perseguir apenas uma entre as quatro áreas do conhecimento - Linguagens e suas tecnologias, Matemáticas e suas tecnologias, Ciências da natureza e suas tecnologias e Ciências humanas e sociais aplicadas -, acrescidas de uma quinta opção, Formação técnica e profissional. A tese sustentada pelo documento é a de que o aluno deve ser protagonista de sua própria formação, podendo escolher o aprofundamento formativo segundo seus interesses pessoais e a partir do que viu em seu processo escolar: "essa nova estrutura valoriza o protagonismo juvenil, uma vez que prevê a oferta de variados itinerários formativos para atender à multiplicidade de interesses dos estudantes" (BRASIL, 2018, p. 467). Sabe-se, no entanto, que esse protagonismo juvenil, divulgado pelo governo inclusive em propagandas televisivas, tem seus limites. Como os itinerários formativos serão organizados segundo "a relevância para o contexto local e a possibilidade dos sistemas de ensino" (BRASIL, 2018, p. 467), e tendo em vista que o Brasil aprovou recentemente a Emenda Constitucional 95, que limita por 20 anos os gastos públicos, tudo indica que os sistemas de ensino e as unidades escolares não conseguirão ofertar todos os cinco itinerários formativos na maioria dos casos, o que deixará o aluno à mercê das reais possibilidades das escolas mais próximas de sua casa. Para ser bastante claro, os contextos escolares mais precarizados, sem um amplo investimento financeiro em contratações e infraestrutura, estão fadados a replicar essa precariedade sob a forma de um ou outro itinerário formativo capaz de ser viabilizado na estrutura já existente. Eduardo F. Mortimer (2018), professor da Faculdade de Educação da UFMG e conselheiro da SBPC, resume a questão da seguinte maneira: 


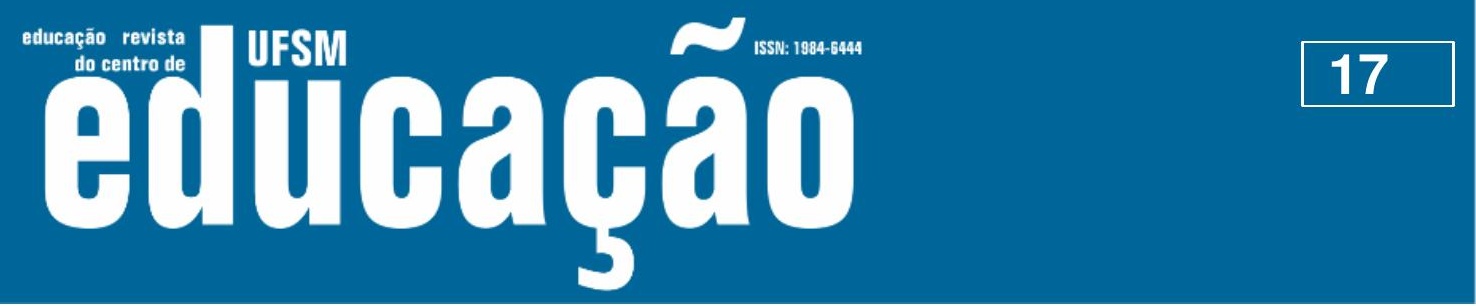

ISSN: 1984-6444 | http://dx.doi.org/10.5902/1984644435680

O que salta aos olhos na lei do Ensino Médio é a não obrigatoriedade de as escolas ofertarem todos os cinco itinerários formativos. [...] $\mathrm{O}$ grande problema da falta de professores no ensino médio, que toca todas as regiões do país, principalmente nas áreas de física e química, evapora-se como num passe de mágica. As escolas, não sendo obrigadas a oferecer todos os itinerários, poderão simplesmente optar por não oferecer, por exemplo, Ciências da Natureza e suas Tecnologias, pois isso baixa o custo do ensino e resolve o problema da falta de professores nessa área. Com certeza as escolas particulares para classe média e alta irão ofertar todos itinerários. Porém, para a escola pública, ofertar certos itinerários significa ter professores da área. Isso vai aumentar ainda mais o fosso que separa as escolas particulares da elite das escolas públicas destinadas a população de baixa renda, ao não permitir que estudantes pobres cursem certas áreas principalmente a de ciências naturais, nas quais há deficiência de professores. A medida condena essa população, que chega com muito esforço e dificuldade ao ensino médio, a cursar apenas os itinerários ofertados por escolas da sua região.

Assim, por trás do discurso neoliberal de escolha individual, liberdade, flexibilidade, criatividade, heterogeneidade e pluralidade - palavras que afloram a todo o momento no texto da BNCC -, surge a preocupação em torno de um alinhamento com as políticas internacionais de avaliação do desempenho estudantil, pautadas via de regra nas disciplinas de português e matemática, e a possibilidade de uma reestruturação da escola que não demande investimento financeiro público. Como dito acima, o risco que se corre é alargar ainda mais o fosso entre a formação oferecida pelos estabelecimentos escolares capazes de dar conta dos cinco itinerários provavelmente escolas particulares - e as unidades que, sem investimento público, permanecerão precariamente inseridas na reforma do ensino médio, tendo de se ajustar ao imediatamente possível. Garantir o direito da juventude e até mesmo suas escolhas, significaria, nesse caso, assegurar uma escola pública de qualidade que vise a diminuir as desigualdades sociais que são, como sabemos, também resultado de um processo de escolarização profundamente desigual. Sobre isso, em particular, a BNCC tem pouco a dizer.

\section{Considerações finais}

No último processo avaliativo do PISA em 2015 o Brasil obteve um resultado aquém do esperado, considerando o avanço em termos de políticas públicas para os 


\section{Tusm Eutirapá}

ISSN: 1984-6444 | http://dx.doi.org/10.5902/1984644435680

constituição de políticas públicas nos países em desenvolvimento baseadas em experiências supostamente positivas (benchmarking) no âmbito educacional provenientes de países desenvolvidos, como no caso dos EUA, Finlândia e Cingapura. O referencial que sustenta estas iniciativas, só leva em consideração o aspecto econômico relacionado à educação, em termos de privilegiar o investimento financeiro e dar mais eficiência e celeridade aos processos de escolarização, nesse caso em específico no Brasil, a reconfiguração curricular por meio da BNCC. Segundo dados do próprio Instituto Ayrton Senna: "A transferência de conhecimentos do campo da gestão para o setor público foi um dos grandes diferenciais das nossas soluções, promovendo eficiência, eficácia e efetividade em prol de uma educação de qualidade" (IAS, 2016).

O tratamento empresarial recebido pela educação brasileira por meio das políticas públicas supracitadas e de seus vínculos com agentes como OCDE e IAS produz como resultado diferentes formas de marginalização e exclusão. No caso específico da BNCC, por exemplo, para além de mencionar apenas uma única vez, ao longo de todo o documento, a Lei n. 10.639/03 - cujo Art. 26-A define que "nos estabelecimentos de ensino fundamental e médio, oficiais e particulares, torna-se obrigatório o ensino sobre História e Cultura Afro-Brasileira" -, não há qualquer discussão, entre outros, sobre Educação Especial, Educação de Jovens e Adultos, Educação do Campo, Educação Escolar Indígena, Educação Escolar Quilombola e Educação a Distância. Com efeito, a única coisa dita é que as diferentes modalidades de ensino citadas terão de se adequar às mudanças ali propostas, como se não houvesse nelas qualquer singularidade e como se não demandassem um debate teórico e político aprofundado acerca de seu lugar decisivo no contexto educacional brasileiro. Essas omissões não nos deixam dúvidas: elas correspondem, na verdade, a uma forma de marginalização e invisibilização num país que, conforme indica a nota da ANPEd (2018), "arrasta atrás de si um longo e profundo histórico de desigualdades educacionais não resolvidas".

Vale notar que todo o esforço noticiado pelas organizações sociais nacionais e pela OCDE junto à educação pública do país dá-se sem qualquer relação com pesquisadores da área ou com os órgãos oficiais nacionais de pesquisa em educação 


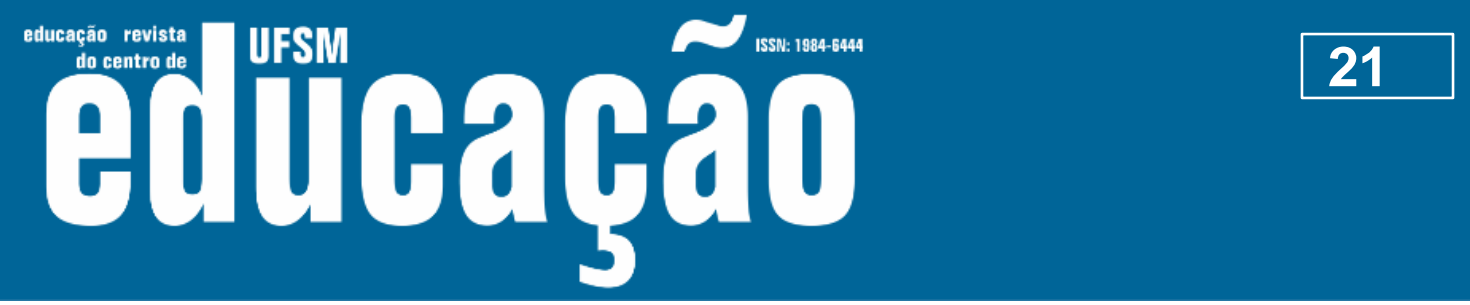

ISSN: 1984-6444 | http://dx.doi.org/10.5902/1984644435680

DOURADO, Luiz Fernandes; OLIVEIRA, João Ferreira de. Base Nacional Comum Curricular (BNCC) e os impactos nas políticas de regulação e avaliação da educação superior. In: AGUIAR, Márcia Angela da S.; DOURADO, Luiz Fernandes (Orgs.). A BNCC na contramão do PNE 2014-2024: avaliação e perspectivas. Recife: ANPAE, 2018, p. 38-43.

FÓRUM INTERNACIONAL DE POLÍTICAS PÚBLICAS “Educar para as competências do século 21", São Paulo. Comunicado de Imprensa. Disponível em: http://www.educacaosec21.org.br/foruminternacional2014/wpcontent/uploads/2014/01/comunicado-de-imprensa-f\%C3\%B3rum.pdf. Acesso em: 12 fev. 2014.

ORGANIZAÇÃO PARA COOPERAÇÃO E DESENVOLVIMENTO ECONÔMICO (OCDE). Estudos da OCDE sobre competências: competências para o progresso social: o poder das competências socioemocionais. São Paulo: Fundação Santillana, 2015.

INSTITUTO AYRTON SENNA (IAS). Nossa história. Disponível em: http://www.institutoayrtonsenna.org.br/pt-br/instituto.html\#a-proposta. Acesso em: 24 fev. 2018.

INSTITUTO AYRTON SENNA (IAS). Um fio, um retalho, uma colcha: práticas de gestores inovadores. Disponível em:

http://www.institutoayrtonsenna.org.br/content/dam/institutoayrtonsenna/atuação/inici ativas/-proposta-de-educação-integral-para-o-ensino-médio-em-santa-

catarina/documents/Instituto_Ayrton_Senna_praticas_de_gestores_inovadores.pdf. Acesso em: 12 fev. 2018.

INSTITUTO AYRTON SENNA (IAS). Estudo especial sobre alfabetismo e competências socioemocionais na população adulta brasileira. São Paulo: Instituto Ayrton Senna/Instituto Paulo Montenegro, 2016.

INSTITUTO FEDERAL DE BRASÍLIA. Rede Federal é destaque na principal avaliação da educação básica do mundo. Disponível em:

http://www.ifb.edu.br/reitori/12838-rede-federal-e-destaque-na-principal-avaliacaoda-educacao-basica-do-mundo. Acesso em: 8 dez. 2016.

Lei n. 9.394, de 20 de dezembro de 1996. Estabelece as Diretrizes e Bases da Educação Nacional. Disponível em:

http://www.planalto.gov.br/ccivil_03/leis//9394.htm. Acesso em: 20 set. 2018.

MARIUZZO, Patrícia; MORALES, Ana Paula. Base Nacional Comum Curricular do Ensino Médio carece de diálogo com a sociedade. Ciência e Cultura. n. 70, vol. 2, 2018, p. 6-9. 


\section{uss \\ 15SN: $1984-6449$

ISSN: 1984-6444 | http://dx.doi.org/10.5902/1984644435680

MORTIMER, Eduardo F. A BNCC do Ensino Médio: entre o sonho e a ficção. Portal SBPC net, São Paulo. Disponível em: http://portal.sbpcnet.org.br/noticias/a-bncc-doensino-medio-entre-o-sonho-e-a-ficcao/. Acesso em: 10 abr. 2018.

SANTOS, Daniel, PRIMI, Ricardo. Desenvolvimento socioemocional e aprendizado escolar: uma proposta de mensuração para apoiar políticas públicas. Relatório sobre resultados preliminares do projeto de medição de competências socioemocionais no Rio de Janeiro. São Paulo: OCDE/SEEDUC/Instituto Ayrton Senna, 2014. Disponível em: http://educacaosec21.org.br/wpcontent/uploads/2013/07/desenvolvimento-socioemocional-e-aprendizadoescolar.pdf. Acesso em: 20 fev. 2018.

SEMIS, Laís. Reforma do Ensino Médio faz Callegari deixar presidência da comissão da BNCC. Nova Escola, São Paulo. Disponível em:

https://novaescola.org.br/conteudo/11912/reforma-do-ensino-medio-faz-callegarideixar-presidencia-da-comissao-da-bncc. Acesso em: 2 jul. 2018.

\section{Correspondência}

Rafael Rodrigo Mueller - Universidade do Extremo Sul Catarinense, Avenida Universitária, 1105, Universitário. CEP 88806-000, Criciúma, Santa Catarina, Brasil.

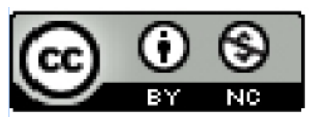

This work is licensed under a Creative Commons Attribution-NonCommercial 4.0 International (CC BY-NC 4.0) 